\title{
A Classification Model for Managers by Competencies: A Case Study in the Construction Sector
}

\author{
Camila Campos Gómez Famá ${ }^{1}$ and Luciana Hazin Alencar ${ }^{2}$ \\ ${ }^{1}$ Management Engineering Department, Universidade Federal de Pernambuco, Av. Professor Moraes Rego, 1235, Cidade Universitária, \\ 50670-901 Recife, PE, Brazil \\ ${ }^{2}$ Center for Decision Systems and Information Development (CDSID), Universidade Federal de Pernambuco (UFPE), \\ Av. Prof. Moraes Rego, 1235, Cidade Universitária, 50670-901 Recife, PE, Brazil
}

Correspondence should be addressed to Luciana Hazin Alencar; alencarlh@gmail.com

Received 14 June 2017; Revised 1 September 2017; Accepted 12 September 2017; Published 12 November 2017

Academic Editor: Juan C. Leyva

Copyright (C) 2017 Camila Campos Gómez Famá and Luciana Hazin Alencar. This is an open access article distributed under the Creative Commons Attribution License, which permits unrestricted use, distribution, and reproduction in any medium, provided the original work is properly cited.

\begin{abstract}
Many companies have difficulties in filling managerial positions. This is because there is a lack in understanding of the competencies that a manager must have. This is as true for those responsible for selecting managers as it is for the employee who aspires to be a manager. Furthermore, the construction industry seeks to appoint managers who are likely to excel in several different managerial roles. However, currently, there is no model that classifies managers by the different competencies they need to perform specific functions. This paper presents how a nonordered classification method was applied in a construction company in order to select managers for different roles. While no manager is considered to be more important than any other, they nevertheless need to have different competencies that match those needed for the job assigned to them. The model also serves as a guide for evaluating whether or not those already in or being considered for a managerial position have the competencies required.
\end{abstract}

\section{Introduction}

According to Firouzi et al. [1], the construction industry is one of the most unreliable industries in terms of controlling project costs and completing jobs on time. Many construction projects exceed the estimated costs and completion date and, subsequently, disputes arise between stakeholders. Increases in the scale and complexity of construction projects have made it all the more difficult to control such projects [2].

Therefore, Hanna et al. [3] say that a strategy for solving these persisting problems and achieving better project performance lies in further study of the human component, particularly project managers (PMs). Russell et al. [4] also affirm that it is PMs who are responsible for ensuring the general success of a construction project, which includes their seeing to it that objectives associated with cost, schedule, quality, and safety are met.

On the assumption that if people who manage and work on projects are competent their performance will be effective and that this leads to projects and organizations being successful, Ofori [5] emphasizes the importance of examining competencies closely above all in private companies. Jantti and Greenhalgh [6] also state that it is only when the competencies needed to develop leadership have been fully identified that greater clarity is given to goals. This is also likely to lead to insights into how a manager can become skilled in a given competency and to determining points of reference that can be evaluated.

In organizations focused on the principles and techniques of project management, several studies [7-10] have recommended that different styles of managing projects, as well as different profiles of competencies and leadership styles of PMs, must be selected appropriately for different types of projects and situations.

Therefore, employees are actively encouraged and supported to participate in leadership programs and engage in other professional development activities. However, despite these efforts, filling leadership positions at both middle and senior levels has been proven to be a challenge recently [6] According to Rashidi et al. [11], selecting a project manager 
for construction projects is one of the most important and, at the same time, one of the most complicated decisions to be made.

One cause of this problem is that both those responsible for selecting PMs and employees who aspire to be in this position lack a good understanding of what skills a PM needs to have [12]. The human reasoning that leads to choosing a candidate is often ambiguous, biased, and lacking in accuracy; yet the existing selection methods do not account for this ambiguity and hence carry little validity and lack efficiency [11].

Thus, it is essential to conduct further research on the dimensions of each of the most critical skills a PM should have in order to provide insight into gaps in the training programs for those in the construction industry as a whole. In addition, it would be helpful for engineering companies to have an assessment tool that would better enable them to identify strengths and weaknesses in key individuals which a company can then use to plan training for professional development [13].

According to Dainty et al. [14] and Hanna et al. [3], although there have been numerous frameworks developed to evaluate PMs, the literature reveals that how the relative importance of PMs' competencies is evaluated has been based on subjective techniques rather than techniques based on empirical data. Furthermore, people who are employed as managers in the construction sector are given different job titles and roles despite the fact that the responsibilities assigned to PMs are often very similar, while in other cases, some roles given to PMs should be undertaken by other managers. Standard guidelines are needed for these matters [15]. Cheng et al. [2] affirm that coordination between different members of the construction team is vital if a project is to run smoothly. They also state that the key element for carrying out a huge construction project is to have a suitable project organizational structure, as this will improve the efficiency of communication between different groups of project members. Thus, in sum, the construction sector lacks a model for classifying managers for different jobs by their competencies.

\section{Relevance of This Paper for the Construction Industry}

The importance of this article for companies in the construction sector arises from reexamining their practice of delegating different functions to the engineers who make up the team assigned to each project. Many projects suffer from implementation failures such as delays, significant increases in estimated costs, and poor quality due to failures in the performance of their managers. The importance of these managers having the competencies needed for projects to succeed has already been highlighted above. However, the various models in the literature assess only the competencies that should be required of PM posts, not the performance of those who fill them, and the current models use subjective approaches.

This article emphasizes the need to classify managers prior to construction companies filling different positions in projects. After classifying managers, a company can then appoint the manager that best suits a particular function, based on their previous performance when measured against the competencies previously defined for the post he/she will fill. In addition, a company may also use the information on managers' previous performance to design and deliver training for managers in competencies in which they have a major deficiency.

\section{Theoretical Relevance of This Paper}

There are several decision problems in our daily life involving multiple criteria, which may be conflicting and unmeasurable. Consequently, implementing solid theoretical structures to structure decision-making processes arises from the complexity of making real-world decisions and the multiplicity of factors that must be taken into account. Multicriteria Decision Aid (MCDA) can be highly useful for decisionmakers (DMs) in such tasks [20].

However, MCDA has many methodologies that tackle classification problems, one of which is the NeXClass method, which was proposed by Rigopoulos et al. [21]. They affirm that NeXClass is a Decision Support System (DSS) that supports classifying alternatives into predefined nonordered categories according to their performance set against evaluation criteria and implements a novel classification algorithm based on multicriteria analysis and outranking relations.

This paper puts forward the NeXClass method in order to classify different types of construction industry managers and then this classification is used to match each manager with the PM position that is the most appropriate for them, based on assessing their competencies and performance on construction projects to date.

This model is relevant to the construction industry since the category of manager does not have a hierarchical order but only requires different competencies according to what function will be exercised. Moreover, using a classification model is of fundamental importance, since this type of model can be used with noncompensatory relations. This is ideal whenever the lack of these competencies will not be counterweighed by others that are at a higher level.

\section{Literature Review}

Competency models began to be developed in the early 1970s. Since then, the two main reasons, emphasized in the literature, for the continuing interest in them are, firstly, their usefulness in responding to changes in organizations and in the workplace and, secondly, the fact that they are a response to the needs of people since competency models can be used in order to meet specific needs within organizations [22].

Thus, Sandwith [23] developed a competency model based on domains, or segments of a job or task, and included aspects of leadership and management, namely, the need to develop interpersonal, conceptual, creative, and technical skills. However, it only focuses on hospitals and the tourism sector. Later, other researchers from other areas felt that there was a need to develop their own competency model based on elements of Sandwith's [24]. 
Goodwin [12] examined the PM's role in relation to the skills needed to fill a PM position. He concluded that a PM's effectiveness depends on his/her conceptual, human, negotiation, and technical skills. However, this study has gaps when it comes to training employees as it does not adequately address how they can acquire other skills, for example, in integration and development, human relations, and communication.

To fill this gap, Gushgari et al. [13] drew up a list of twenty skills that they considered were critical, or very important, for PMs to have, and they also listed what they deemed as the preferred methods of training members of an organization.

The research limitations in Gushgari et al. [13] are that they compiled this list of skills based on interviews and did not consider how such skills are deployed in practice nor did they measure managers' performance after they had been trained. Thus, this article puts forward a model that allows top management to measure managers' performance as well as giving suggestions on identifying possible deficiencies in current training.

Arditi and Balci [18] evaluated the managerial competencies of female PMs and compared the results with those of male PMs in the context of the construction industry. However, the assessment of managers' competencies took into account neither the managers' performance nor the team's competencies during the project. Therefore, Margerison [25] proposed a competencies model for teams based on the fact that, given global competition and technological advances, organizational success depends more on a team's efforts than on an individual's.

Dulewicz and Higgs [26] demonstrated that there is little correlation between leaders' competencies and functions and commonly identified staff behaviors; only some roles within a team and personality factors are correlated with a leader's performance. These authors suggested that three types of competencies, namely, intellectual, management, and emotional competencies, explained much of managerial performance. They measured these leadership constructs and also the organizational context in terms of the degree of change that a leader needs to undergo. In addition, they show that a leader's performance depends on the relationship between leadership styles and the type of project itself; namely, different leadership styles achieve better or worse outcomes (relatively stable, significant change of context; transformational change). However, application of their study is limited to the private sector only and does not incorporate measures of performance at work nor does it investigate the link between style and context.

Cheng et al. [16] studied PMS in the construction industry. A list of criteria to measure excellence in performance was drawn up by a focus group of key stakeholders and used to identify a "superior" group of managers and an "intermediate" group. Interviews with "superior" level managers were used to identify competencies associated with high performance. The results indicated that senior managers could be distinguished from middle managers by measuring 12 competencies. However, this study has limitations, since the managers' training and development was only based on the competencies it measured.
In order to identify competencies in the project management area, Ofori [5] conducted an exploratory study using a sample of 200 intentionally selected managers. In this instance, competence scores were used to determine management competence levels in organizational projects. The research used a structured, two-part questionnaire as the basis of collecting primary data. The first part collected demographic data from respondents, while the second part sought information about knowledge and skill levels as a proxy to determine the respondents' competency levels in a number of project management areas [5]. Nevertheless, the study did not assess the most important competencies for each type of management nor did it consider the fact that managers in different jobs require different competencies.

Hanna et al. [3] distinguish outstanding PMs from average ones and reflect on the relative importance that professionals in the construction industry attribute to each competence of a PM. By using an additive model in their research, they consider that a PM's particular deficiency in a competence area could be compensated by another where this same PM has greater success. In this case, whatever important competencies for success that PMs have in a given project could be balanced by others that are less necessary. However, the study focuses only on PMs, without considering other posts and the activities that holders of these other posts undertake in the construction sector. In other words, the study ignores the fact that the competencies or mix of competencies needed by holders of different posts with different functions vary from project to project.

\section{Multicriteria Approach}

MCDA seeks to support DMs to organize and summarize information in a way that makes them feel comfortable and confident when they make decisions. MCDA is used to assess multiple objectives, which are variables that frequently have different measurement units, in an integrated manner [20].

The classification used in this article is to allocate a set of alternatives into predefined homogeneous classes [27]. According to Rigopoulos et al. [21], classification methods are divided into two groups: supervised and unsupervised groups. The supervised group is when we have data or cases with predefined classes and the objective is to build a model to classify unlabeled data; that is, these data will be classified in predefined classes. Depending on whether categories are ordered or not, they are defined as sorting or classification. The unsupervised group is when we have the unlabeled data to cluster them into different clusters, based on appropriate algorithms. Categories are not predefined, and this approach is denoted as clustering. Doumpos and Zopounidis [27] emphasize that the difference between classification and clustering is that in classification problems the groups are defined a priori, whereas in clustering the objective is to identify groups (clusters) of alternatives sharing similar characteristics.

Among the existing classification methods, the following stand out for our purposes: ELECTRE TRI which is based on the outranking relations approach $[28,29]$; the UTADIS 
method, a classification model using an additive utility function ([27, 30]); and the fuzzy method PROAFTN [31].

However, to apply PROAFTN, the values of several parameters need to be determined prior to classification, such as boundaries of intervals, weights, and preference thresholds. In an MCDA context, defining what the "boundaries" of the attributes and the weights are depends on the DM's judgment. Unfortunately, this process is complex so it is often difficult for a DM to assign accurate quantitative values to these parameters. Moreover, the parameters that represent the preferences are often unclear and may change over time [32].

NeXClass differs from all the existing methods in that it introduces a novel classification method based on a threshold entry level for each category instead of a central category prototype. Another benefit of the proposed methodology is that DMs can use it whenever the number of training data sets is low or is difficult to define [21].

According to Rigopoulos et al. [21], the NeXClass methodology (Figure 1) is a classification method based on an entry-level limit for each category. This is a noncompensatory method with nominal classes which this article uses to assign managers to different roles in a project in the construction sector in accordance with how their skills have been evaluated.

\section{Methods}

This article puts forward a method based on MCDA concepts which classifies managers in the construction industry in terms of their ability to perform different roles. This is measured against their performance in the competencies that are most appropriate and which such a professional in each of these roles needs to have in order to be successful in their respective duties.

In addition to identifying competencies and their level of importance in predetermined jobs, the proposed method also offers guidelines on how to evaluate whether or not managers have such competencies. These guidelines are based on conclusions drawn from reviewing the literature and propose what kind of training is best suited to overcome weaknesses identified that a PM may have in some of the competencies. Finally, feedback is provided on factors that were critical for the project's success or failure.

The research approach is carried out in three stages: (1) describing the problem, (2) applying the MCDA method in the company studied, and (3) evaluating the results. The sequence of steps is given in Figure 2.

6.1. Step 1: Describing the Problem. The main objectives of this stage are to describe the research problem and to do so by drawing on observations made from reviewing the literature and to conduct an exploratory study of the company.

6.1.1. Description of the Company and Its Managers. The construction company in the study is currently running six projects and directly employs approximately 650 people. The team includes 12 civil engineers: the director, the cost manager, the schedule manager, the contract manager, the

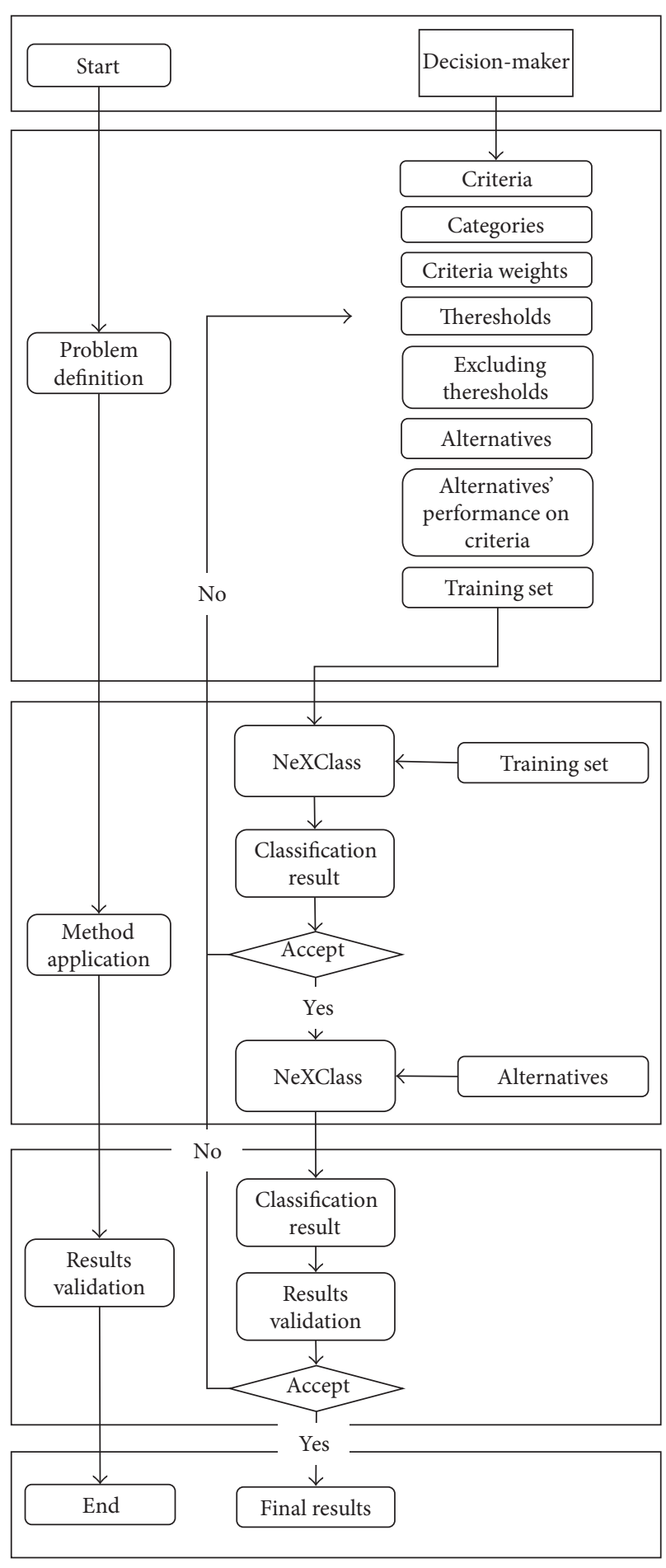

FIGURE 1: NeXClass algorithm [20].

quality manager, and the project manager and the other six are residents.

Although there are no major flaws in how projects are carried out, problems such as late delivery of buildings and increases in budget costs are frequent, causing the company's top management to feel the need to micromanage their active managers to ensure that projects progress efficiently. 


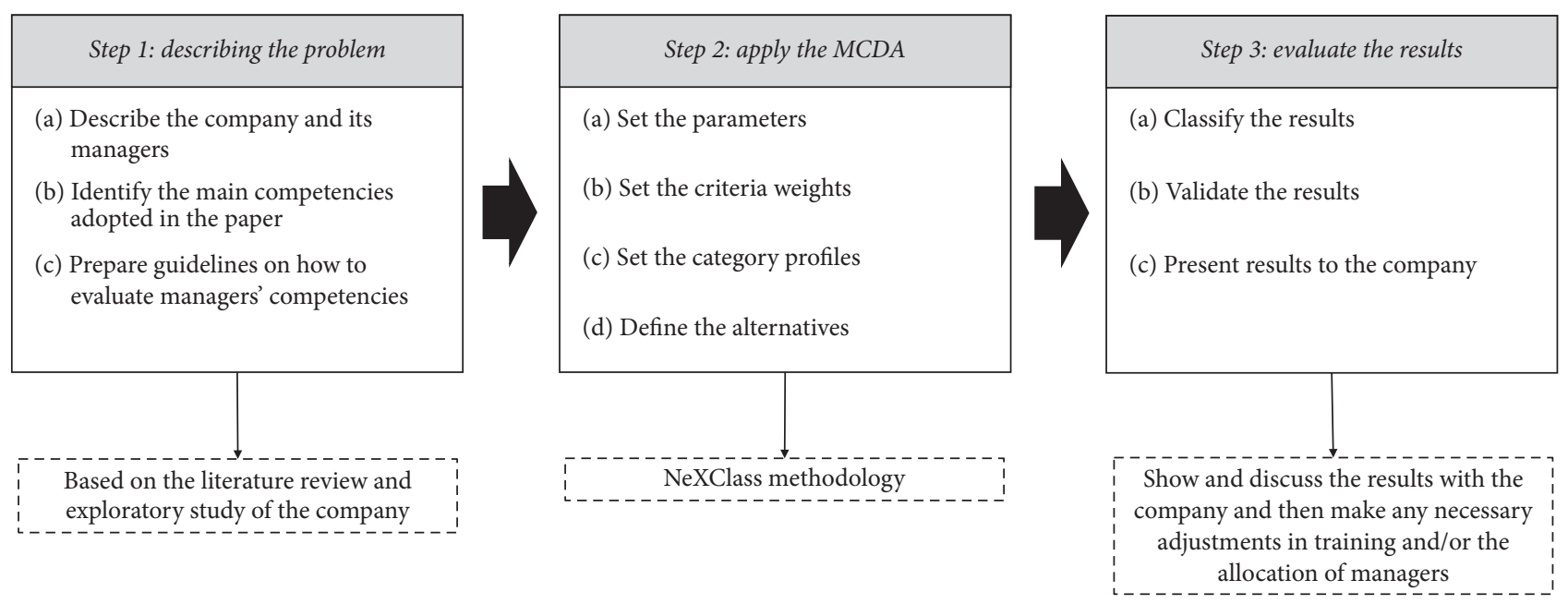

FIGURE 2: Steps for applying the NeXClass method so as to classify managers by competencies.

Therefore, this article set out to verify, by applying the classification model NeXClass, if the managers currently assigned had the most appropriate competencies in each one of their functions and if these enabled them to exercise their respective positions. Otherwise, projects in progress could be hampered by the lack of competence of one or more of their managers. One solution to this problem would be to train the manager in the competency in which he presents a deficiency or, alternatively, to assign managers to other positions.

In the present study, the DM was identified as the director, since he was responsible for changing the function of some managers at the end of each project. The five positions chosen, which are listed below and to which the method was applied, were only those that changed from project to project. Their functions were defined by the director and also from some of those identified from the literature (see $[33,34]$ ).

$C_{1}$ : Cost Manager. The cost manager must be a proficient estimator with capabilities ranging from conceptual design to drawing up construction documents and must be knowledgeable about the requirements and mechanics of project budgets. He/she must also have a broad and accurate understanding of project expenses besides construction costs.

$C_{2}$ : Schedule Manager. The schedule manager must not only be an excellent scheduling technician; he/she must know what types of schedules will be most effective in every situation and how to make scheduling work effectively on a project. Also, he/she must have a full understanding of the time requirements for all aspects and elements of project delivery, as well as intimate knowledge of production rates of geographically located construction trades.

$C_{3}$ : Contract Manager. The contract manager must have experience in all the facets of contracting which might emerge during the project. Some of these consist of awareness of contract language/requirements, contract procedures, labor relations, passive and active contract enforcement, liability and forms of property insurance, contracting forms of surety, standards of performance, contractor procedures, construction safety, testing and quality practices, dispute resolution, contractor qualification, purchasing practices, design office practice, subcontracting, consultant practices, and other unstated facets inherent to project delivery.

$C_{4}$ : Quality Manager. In order to contribute to setting quality standards, the quality manager must possess expertise in specifying materials and equipment. To develop a quality management program that effectively monitors both the design and construction processes, he/she must also have an intimate knowledge of the functions of both the design professional and trade contractors. These abilities must be adequately available in any quality manager considered by the DM.

$C_{5}$ : Project Manager. Project manager coordinates all of those functional specialists (i.e., designers, estimators, purchasers, and constructors) who are required for the particular project. $\mathrm{He} /$ she must have experience in their area of expertise and in project management; he/she must have mastered techniques, management processes, and tools and preferably must be specialized in the project area or possess an international certification in construction management.

6.1.2. Identify the Main Competencies Adopted in the Paper. Assuming that the company's managers were assessed on their knowledge of and abilities in management functions, the study sought to define a set of appropriate assessment criteria, namely, those used to evaluate the most important aspects of a managers' performance, and the level of competence they achieved when matched against each of these criteria. The criteria selected, and how these were defined, were based on observations made after reviewing the literature.

These competencies were divided into three groups: intellectual, management abilities, and emotional. The first group covers those related to technical and scientific aspect of the job; the reality of the organization, processes, products, the market, and technology; models and instruments of 
management; knowledge of mechanisms of human interaction at work; and theories of leadership, motivation, creativity, and teamwork. Managerial ability concerns the skills required to achieve positive results in human interaction, to tackle process management successfully, and to constantly search for quality. The emotional group entails being able to manage successfully the emotional, behavioral, and motivational factors of an individual.

6.1.3. Prepare Guidelines on How to Evaluate Managers' Competencies. Having described the problem and its values, the study proposes a guide to identify whether each class of managers already has the competencies that the Guide suggests it should have. Therefore, the main objective of the guide was to use it as a means to indicate the main limitations of the company's managers: in their respective assignments or classes. Thus, each criterion was presented and explained to the company's top management, which was responsible for evaluating the managers. The evaluation was made by using a nominal scale from 1 to 5 , where $1=$ very competent (VC); 2 = competent (C); 3 = somewhat competent (SC); 4 $=$ uncertain $(\mathrm{U})$; and $5=$ not competent $(\mathrm{NC})$. The meaning of each of these levels for each of the criteria is explained in the Appendix, which also presents the guide for measuring the criteria which is adapted from the study of Ofori [5].

6.2. Step 2: Apply the MCDA-NexClass Method. The application of the NeXClass method set out to classify company managers by predefined classes using the competencies listed in Table 1.

6.2.1. Set the Parameters. The NeXClass methodology is represented by an algorithm which has the following notation:

(1) $A=\left\{a_{1}, a_{2}, \ldots, a_{m}\right\}$ : a set of alternatives which are to be classified into a number of categories.
(2) $G=\left\{g_{1}, g_{2}, \ldots, g_{n}\right\}$ : a set of evaluation criteria.

(3) $C=\left\{C^{1} ; C^{2} ; \ldots, C^{k}\right\}$ : a set of categories.

(4) $B^{h}=\left\{b_{1}^{h}, b_{2}^{h}, \ldots, b_{k}^{h}\right\}$ : a set of prototypes for category $h$, where $B^{h}=\left\{b_{i}^{h} \mid i=1, \ldots, k, h=1, \ldots, L_{h}\right\}$ and $b_{i}^{h}$ is the $i$ th prototype of the $h$ th category. These prototypes define the category as thresholds of entrance into a category.

(5) The performance of the alternatives against the criteria is calculated in such a way that $¥ a, g(a)=$ $\left(g_{1}(a), g_{2}(a), \ldots, g_{n}(a)\right)$ and $¥ b_{i}^{h}, g\left(b_{i}^{h}\right)=\left(g_{1}\left(b_{i}^{h}\right)\right.$, $\left.g_{2}\left(b_{i}^{h}\right), \ldots, g_{n}\left(b_{i}^{h}\right)\right)$.

Two processes are used to perform allocations: an optimistic one and a pessimistic one. In the case of the pessimistic process, the alternatives are compared successively to reference profiles $b_{h}$, starting with the ordering of the best alternatives. The process then moves on to the next reference profile $b_{h}$ until the credibility index exceeds the cutting level. At that point, the process allocates alternative " $a$ " to the delimited category for that lower reference profile.

In the case of the optimistic process, the comparison begins with the worst reference profile $b_{h}$. The process then moves on to the next profile until reference profile $b_{h}$ is found, where the credibility index exceeds the cutting level. When that occurs, alternative " $a$ " is allocated to the category defined as the highest by reference profile $b_{h}$.

The NeXClass algorithm was implemented by using the following steps:

(i) Compute the partial concordance index $\left[c_{j}\left(a, b_{i}^{h}\right)\right.$, $\left.c_{j}\left(b_{i}^{h}, a\right)\right](\operatorname{see}(1))$ :

$$
\begin{gathered}
c_{j}\left(a, b_{i}^{h}\right)= \begin{cases}0, & g_{j}(a) \leq g_{j}\left(b_{i}^{h}\right)-p_{j}\left(b_{i}^{h}\right), \\
\frac{g_{j}(a)-g_{j}\left(b_{i}^{h}\right)+p_{j}\left(b_{i}^{h}\right)}{p_{j}\left(b_{i}^{h}\right)-q_{j}\left(b_{i}^{h}\right)}, & g_{j}(a) \in\left(g_{j}\left(b_{i}^{h}\right)-p_{j}\left(b_{i}^{h}\right), g_{j}\left(b_{i}^{h}\right)-q_{j}\left(b_{i}^{h}\right)\right),\end{cases} \\
c_{j}\left(b_{i}^{h}, a\right)= \begin{cases}0, & g_{j}(a) \geq g_{j}\left(b_{i}^{h}\right)-q_{j}\left(b_{i}^{h}\right), \\
\frac{g_{j}\left(b_{i}^{h}\right)-g_{j}(a)+p_{j}\left(b_{i}^{h}\right)}{p_{j}\left(b_{i}^{h}\right)-q_{j}\left(b_{i}^{h}\right)}, & g_{j}(a) \geq g_{j}\left(b_{i}^{h}\right)+p_{j}\left(b_{i}^{h}\right), \\
1, & g_{j}(a) \leq g_{j}\left(b_{i}^{h}\right)+q_{j}\left(b_{i}^{h}\right), g_{j}\left(b_{i}^{h}\right) .\end{cases}
\end{gathered}
$$

(ii) Compute the global concordance index $c\left(a, b_{h}\right)$ and $c\left(b_{h}, a\right)(\operatorname{see}(2))$ :

$$
C\left(b_{i}^{h}, a\right)=\sum_{i=1}^{n} \omega_{i} c_{j}\left(b_{i}^{h}, a\right) .
$$

$$
C\left(a, b_{i}^{h}\right)=\sum_{i=1}^{n} \omega_{i} c_{j}\left(a, b_{i}^{h}\right)
$$

(iii) Compute the discordance index $d_{j}\left(a, b_{h}\right)$ and $d_{j}\left(b_{h}, a\right)$ (see (3)): 


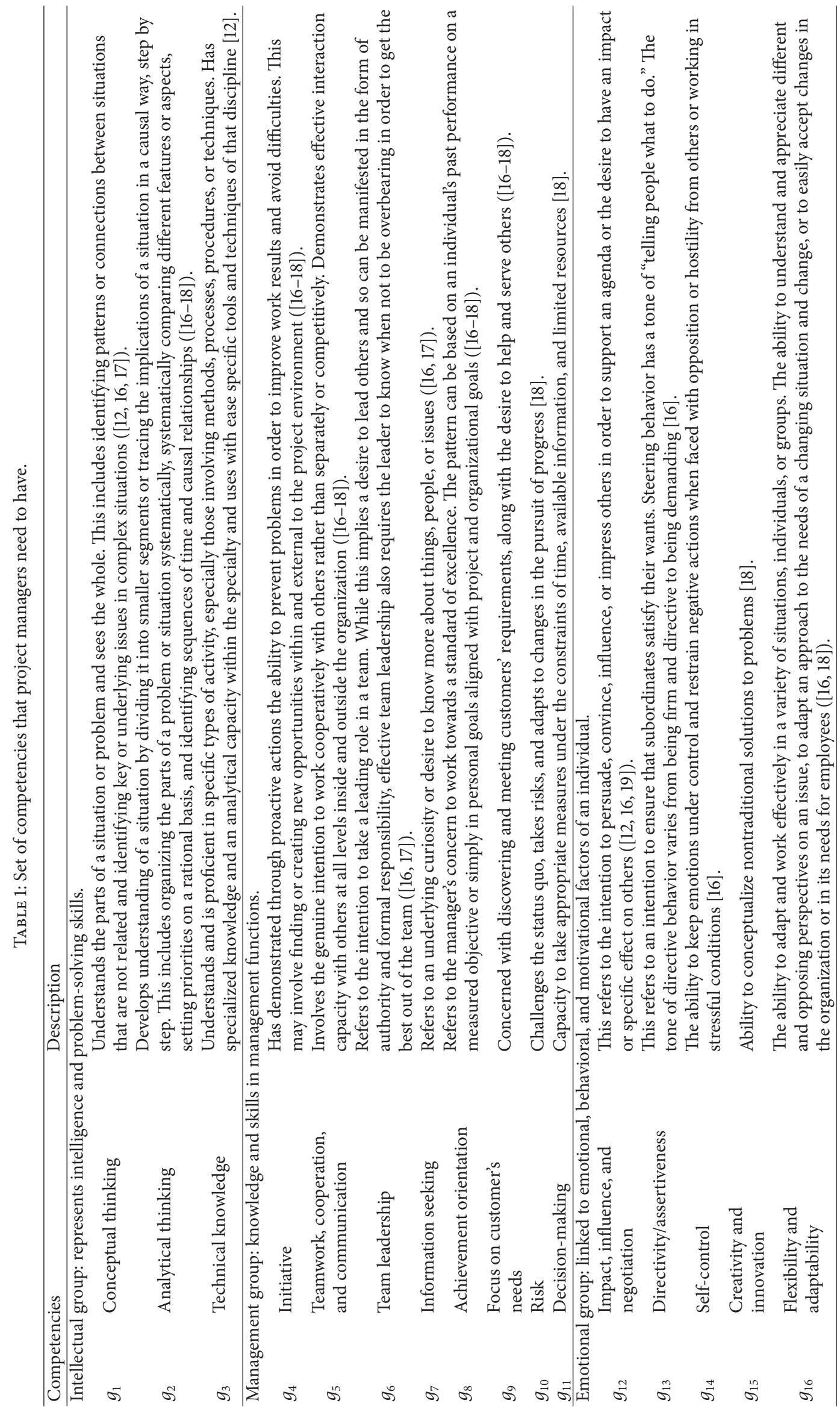


TABLE 2: Ranking of the competencies needed by managers.

\begin{tabular}{|c|c|c|}
\hline Rank & Subset of ex aequo & Number of cards by rank \\
\hline 1 & $\begin{array}{l}\text { (i) Conceptual thinking }\left(g_{1}\right) \\
\text { (ii) Analytical thinking }\left(g_{2}\right)\end{array}$ & 2 \\
\hline 2 & (i) Risk $\left(g_{10}\right)$ & 1 \\
\hline 3 & $\begin{array}{l}\text { (i) Creativity and innovation }\left(g_{15}\right) \\
\text { (ii) Focus on customer's needs }\left(g_{9}\right)\end{array}$ & 2 \\
\hline 4 & (i) White card & 1 \\
\hline 5 & $\begin{array}{l}\text { (i) Self-control }\left(g_{14}\right) \\
\text { (ii) Flexibility and adaptability }\left(g_{16}\right)\end{array}$ & 2 \\
\hline 6 & $\begin{array}{l}\text { (i) Technical knowledge }\left(g_{3}\right) \\
\text { (ii) Impact, influence, and negotiation } \\
\left(g_{12}\right) \\
\text { (iii) Directivity/assertiveness }\left(g_{13}\right)\end{array}$ & 3 \\
\hline 7 & $\begin{array}{l}\text { (i) Achievement orientation }\left(g_{8}\right) \\
\text { (ii) Initiative }\left(g_{4}\right) \\
\text { (iii) Information search }\left(g_{7}\right)\end{array}$ & 3 \\
\hline 8 & (i) White card & 1 \\
\hline 9 & (i) Team leadership $\left(g_{6}\right)$ & 1 \\
\hline 10 & (i) Decision-making $\left(g_{11}\right)$ & 1 \\
\hline 11 & $\begin{array}{l}\text { (i) Teamwork, cooperation, and } \\
\text { communication }\left(g_{5}\right)\end{array}$ & 1 \\
\hline
\end{tabular}

$$
\begin{aligned}
& d_{j}\left(a, b_{i}^{h}\right)= \begin{cases}0, & g_{j}(a) \geq g_{j}\left(b_{i}^{h}\right)-p_{j}\left(b_{i}^{h}\right), \\
\frac{g_{j}\left(b_{i}^{h}\right)-g_{j}(a)-p_{j}\left(b_{i}^{h}\right)}{v_{j}\left(b_{i}^{h}\right)-p_{j}\left(b_{i}^{h}\right)}, & g_{j}(a) \in\left(g_{j}\left(b_{i}^{h}\right)-v_{j}\left(b_{i}^{h}\right), g_{j}\left(b_{i}^{h}\right)-p_{j}\left(b_{i}^{h}\right)\right), \\
1, & g_{j}(a) \leq g_{j}\left(b_{i}^{h}\right)-v_{j}\left(b_{i}^{h}\right),\end{cases} \\
& \gamma_{i}\left(a, b_{i}^{h}\right)= \begin{cases}C\left(a, b_{i}^{h}\right), & \text { If } d_{j}\left(a, b_{i}^{h}\right)<C\left(a, b_{i}^{h}\right), \\
C\left(a, b_{i}^{h}\right) \prod \frac{1-d_{j}\left(a, b_{i}^{h}\right)}{1-C\left(a, b_{i}^{h}\right)}, & \text { Otherwise. }\end{cases}
\end{aligned}
$$

(iv) Compute the excluding degree $\gamma_{i}^{\text {tot }}=\gamma_{i}\left(b_{i}^{h}, a\right) /(1+$ $\left.\gamma_{i}\left(a, b_{i}^{h}\right)\right)$ of the subordination relationship (see (4)):

$$
\begin{aligned}
& \gamma_{i}\left(b_{i}^{h}, a\right) \\
& = \begin{cases}C\left(b_{i}^{h}, a\right), & \text { If } d_{j}\left(b_{i}^{h}, a\right)<C\left(b_{i}^{h}, a\right), \\
C\left(b_{i}^{h}, a\right) \prod \frac{1-d_{j}\left(b_{i}^{h}, a\right)}{1-C\left(b_{i}^{h}, a\right)}, & \text { otherwise. }\end{cases}
\end{aligned}
$$

6.2.2. Set the Criteria Weights. The criteria weights were defined according to the DM's preferences, in this case, the top level manager. To establish these weights, we used the Simos method [35].

Initially, a set of cards containing the name of each criterion (competence) was given to the DM. White cards of the same size were also given out which had additional information that described these competencies. Then the DM had to classify these cards (or criteria) from the least important to the most important. If certain criteria had the same importance (i.e., same weight), he created a subset of cards. Consequently, a complete preorder of all the $n$ criteria was obtained, where $\bar{n}$ is the number of categories for this preorder (most of these categories being reduced to just one card or a single criterion). The first category is named Rank 1 , the second one Rank 2, and so on.

In line with senior management's preferences, the managers' most important competencies were defined in a ranking order (see Table 2).

The weight ratio is given by (5), where " $T$ " is the total number of cards, " $q$ " is a subset of the most important criteria, and " $p$ " is the subset of less important criteria. In the present study, $T=18, q=1$, and $p=2$. Thus, the value of $z$ is equal to 12 .

$$
z=\frac{\left(\sum_{i=0}^{q-1}(T-i)\right) p}{\left(\sum_{i=0}^{p-1}(1+i)\right) q}
$$


TABLE 3: Determining the normalized weights of each criterion for $w=2$ and $z=12$.

\begin{tabular}{|c|c|c|c|c|c|c|}
\hline Rank & Criteria & Normalized weights $k_{i}^{*}$ & Norm. w. $k_{i}^{\prime \prime}$ & Ratio $d_{i}$ & Ratio $\bar{d}_{\iota}$ & Norm. w. $k_{i}$ \\
\hline 1 & $g_{1}$ & 0.982318271 & 0.98 & 0.007820000 & 0.002360000 & 0.98 \\
\hline 1 & $g_{2}$ & 0.982318271 & 0.98 & 0.007820000 & 0.002360000 & 0.98 \\
\hline 2 & $g_{10}$ & 2.062868369 & 2.06 & 0.003457143 & 0.001390476 & 2.06 \\
\hline 3 & $g_{15}$ & 4.223968566 & 4.22 & 0.001427907 & 0.000939535 & 4.22 \\
\hline 3 & $g_{9}$ & 4.223968566 & 4.22 & 0.001427907 & 0.000939535 & 4.22 \\
\hline 4 & $g_{14}$ & 5.304518664 & 5.30 & 0.001033333 & 0.000851852 & 5.30 \\
\hline 4 & $g_{16}$ & 5.304518664 & 5.30 & 0.001033333 & 0.000851852 & 5.30 \\
\hline 5 & $g_{3}$ & 6.385068762 & 6.38 & 0.000772308 & 0.000793846 & 6.39 \\
\hline 5 & $g_{12}$ & 6.385068762 & 6.38 & 0.000772308 & 0.000793846 & 6.39 \\
\hline 5 & $g_{13}$ & 6,385068762 & 6.38 & 0.000772308 & 0.000793846 & 6,39 \\
\hline 6 & $g_{8}$ & 8.546168959 & 8.54 & 0.000448276 & 0.000721839 & 8.55 \\
\hline 6 & $g_{4}$ & 8.546168959 & 8.54 & 0.000448276 & 0.000721839 & 8.55 \\
\hline 6 & $g_{7}$ & 8.546168959 & 8.54 & 0.000448276 & 0.000721839 & 8.55 \\
\hline 7 & $g_{6}$ & 9.626719057 & 9.62 & 0.000340816 & 0.000697959 & 9.63 \\
\hline 8 & $g_{11}$ & 10.707269155 & 10.70 & 0.000255046 & 0.000678899 & 10.71 \\
\hline 9 & $g_{5}$ & 11.787819253 & 10.78 & 0.000185000 & 0.000663333 & 11.79 \\
\hline Sum & 16 & 100 & 99.92 & & & 100.01 \\
\hline
\end{tabular}

Table 3 shows the normalized weights of each criterion for $w=2$.

6.2.3. Set the Category Profiles. After creating the guide, it was necessary to know what the most important competencies would be for each class of managers, since it would be difficult for the same employee to be excellent in all competencies at the same time. Next, the category limits were defined by setting appropriate values for each criterion. The profile of each category of managers was defined by applying the questionnaire shown in the Appendix to the company's senior management for which the results are shown in Table 4.

6.2.4. Define the Alternatives. A subgroup of five engineers was selected at random in the company. The performance of the alternatives against the evaluation criteria was defined by top management. Their answers to the questionnaire which was used to evaluate the competencies that managers need are shown in the Appendix. The questionnaire reveals what the ability of each manager is in the various competencies mentioned above. The responses are shown in Table 5.

6.3. Step 3: Evaluate the Results. In Step 3, the results of the classification and validation are shown and discussed with the company after which they may be adjusted and then the final results are presented.

6.3.1. Classify the Results. The company's managers were classified in accordance with predefined categories, based on the core competencies obtained from applying the NeXClass model, explained in Step 2. The classification is shown in Table 6.

From Table 6 , it can be seen that the $a_{1}, a_{2}$, and $a_{5}$ alternatives of managers have higher values of $\gamma^{\text {tot }}$ in class $C_{4}$ referring to the quality manager. This fact occurs due to the lower level of competencies that managers require to exercise this position. Also it can be verified that the alternative of manager $a_{3}$ was more apt to act like a schedule manager and that manager $a_{4}$ was vetoed to exercise any function due to the low level of his competencies.

6.3.2. Validate the Results. In order for each manager to act in a particular class, Table 6 was adjusted so that the manager of the $a_{1}$ alternative was assigned to act as the quality manager, since his level of competencies, according to $\gamma^{\text {tot }}$, was a little lower than that of other managers and thus was more appropriate for a position that requires a lower level of competencies. Table 7 shows the new classification of managers for each position.

6.3.3. Presentation of Results to the Company. The revised results were presented to the company, based on which it appears that managers represented by alternatives $a_{1}$ and $a_{2}$ have similar profiles to those required for the position of quality manager. This can be explained by the range and level of competencies needed for this job being lower than those for more critical management jobs.

Manager $a_{3}$ can assume the role of schedule manager, while manager represented by alternative $a_{5}$ can work as a cost manager. None of the managers surveyed had the competencies necessary to exercise the role of contract manager $\left(C_{3}\right)$ or of project manager $\left(C_{5}\right)$. However, the model can be used to find out what competencies managers require for such positions which they do not currently have.

Also, the manager of alternative $a_{4}$ has an insufficient level of competencies to assume the positions evaluated. In this case, this manager needs to be trained, especially in the following competencies: initiative $\left(g_{4}\right)$; teamwork, cooperation, and communication $\left(g_{5}\right)$; and team leadership $\left(g_{5}\right)$. 
TABLE 4: Category profiles.

\begin{tabular}{lccccccccccccccccc}
\hline & $g_{1}$ & $g_{2}$ & $g_{3}$ & $g_{4}$ & $g_{5}$ & $g_{6}$ & $g_{7}$ & $g_{8}$ & $g_{9}$ & $g_{10}$ & $g_{11}$ & $g_{12}$ & $g_{13}$ & $g_{14}$ & $g_{15}$ & $g_{16}$ \\
\hline$C_{1}$ & 2 & 2 & 2 & 3 & 1 & 2 & 1 & 2 & 2 & 2 & 2 & 3 & 3 & 3 & 2 & 2 \\
Indif & 1 & 1 & 1 & 1 & 1 & 1 & 1 & 1 & 1 & 1 & 1 & 1 & 1 & 1 & 1 & 1 \\
Pref & 2 & 2 & 2 & 2 & 2 & 2 & 2 & 2 & 2 & 2 & 2 & 2 & 2 & 2 & 2 & 2 \\
Veto & 3 & 3 & 3 & 4 & 3 & 3 & 3 & 3 & 3 & 3 & 3 & 4 & 4 & 4 & 3 & 3 \\
$C_{2}$ & 1 & 1 & 1 & 3 & 3 & 3 & 1 & 2 & 2 & 2 & 2 & 3 & 3 & 3 & 2 & 2 \\
Indif & 1 & 1 & 1 & 1 & 1 & 1 & 1 & 1 & 1 & 1 & 1 & 1 & 1 & 1 & 1 \\
Pref & 2 & 2 & 2 & 2 & 2 & 2 & 2 & 2 & 2 & 2 & 2 & 2 & 2 & 2 & 2 \\
Veto & 3 & 3 & 2 & 4 & 4 & 4 & 3 & 3 & 3 & 3 & 3 & 4 & 4 & 4 & 3 \\
$C_{3}$ & 2 & 2 & 2 & 2 & 1 & 1 & 2 & 2 & 2 & 2 & 2 & 1 & 1 & 1 & 2 \\
Indif & 1 & 1 & 1 & 1 & 1 & 1 & 1 & 1 & 1 & 1 & 1 & 1 & 1 & 1 & 1 \\
Pref & 2 & 2 & 2 & 2 & 2 & 2 & 2 & 2 & 2 & 2 & 2 & 2 & 2 & 2 & 2 \\
Veto & 3 & 3 & 3 & 3 & 3 & 3 & 3 & 3 & 3 & 3 & 3 & 3 & 3 & 3 & 3 \\
$C_{4}$ & 3 & 3 & 2 & 3 & 3 & 3 & 1 & 2 & 1 & 3 & 3 & 3 & 3 & 3 & 2 \\
Indif & 1 & 1 & 1 & 1 & 1 & 1 & 1 & 1 & 1 & 1 & 1 & 1 & 1 & 1 & 1 \\
Pref & 2 & 2 & 2 & 2 & 2 & 2 & 2 & 2 & 2 & 2 & 2 & 2 & 2 & 2 & 2 \\
Veto & 4 & 4 & 3 & 4 & 4 & 4 & 3 & 3 & 3 & 4 & 4 & 4 & 4 & 4 & 3 \\
$C_{5}$ & 1 & 2 & 2 & 1 & 2 & 1 & 1 & 2 & 2 & 1 & 1 & 1 & 2 & 1 \\
Indif & 1 & 1 & 1 & 1 & 1 & 1 & 1 & 1 & 1 & 1 & 1 & 1 & 1 & 1 \\
Pref & 2 & 2 & 2 & 2 & 2 & 2 & 2 & 2 & 2 & 2 & 2 & 2 & 2 & 2 \\
Veto & 3 & 3 & 3 & 4 & 3 & 3 & 4 & 3 & 3 & 4 & 3 & 3 & 3 & 3 \\
\hline
\end{tabular}

TABLe 5: Performance of the alternatives after being evaluated by the criteria.

\begin{tabular}{ccccccccccccccccc}
\hline & $g_{1}$ & $g_{2}$ & $g_{3}$ & $g_{4}$ & $g_{5}$ & $g_{6}$ & $g_{7}$ & $g_{8}$ & $g_{9}$ & $g_{10}$ & $g_{11}$ & $g_{12}$ & $g_{13}$ & $g_{14}$ & $g_{15}$ & $g_{16}$ \\
\hline$a_{1}$ & 1 & 1 & 1 & 2 & 3 & 3 & 2 & 1 & 1 & 1 & 2 & 2 & 2 & 2 & 2 & 2 \\
$a_{2}$ & 2 & 2 & 2 & 1 & 3 & 3 & 1 & 2 & 2 & 2 & 2 & 1 & 2 & 1 & 3 & 1 \\
$a_{3}$ & 3 & 3 & 1 & 2 & 1 & 1 & 2 & 3 & 3 & 1 & 2 & 2 & 1 & 2 & 1 & 3 \\
$a_{4}$ & 1 & 2 & 1 & 4 & 4 & 4 & 2 & 2 & 2 & 1 & 1 & 3 & 3 & 2 & 2 & 2 \\
$a_{5}$ & 3 & 3 & 1 & 1 & 1 & 2 & 2 & 2 & 2 & 1 & 1 & 2 & 1 & 3 & 1 & 3 \\
\hline
\end{tabular}

TABLE 6: Classification of the alternatives by category.

\begin{tabular}{lcc}
\hline Alternatives & Classes & $\gamma^{\text {tot }}$ \\
\hline$a_{1}$ & $C_{4}=$ quality manager & 0.51 \\
$a_{2}$ & $C_{4}=$ quality manager & 0.57 \\
$a_{3}$ & $C_{2}=$ schedule manager & 0.57 \\
$a_{4}$ & Veto & \\
$a_{5}$ & $C_{4}=$ quality manager & 0.62 \\
\hline
\end{tabular}

\section{Discussion}

From the point of view of the company involved in the study, the model proved that it could make a valuable contribution especially with regard to identifying gaps in competencies presented by the managers evaluated. The model's benefit for the company is that it orientates the most suitable manager for each of project roles. It also can be used to evaluate managers, while a project is in progress by using the questionnaire presented in the Appendix. However, one of the problems cited by the company is the time spent in applying the model. This fact can be explained because it was the first time the company used the model; however, it is better to invest
TABLE 7: New classification of the managers for available positions.

\begin{tabular}{lcc}
\hline Alternatives & Classes & $\gamma^{\text {tot }}$ \\
\hline$a_{1}$ & $C_{4}=$ quality manager & 0.51 \\
$a_{2}$ & $C_{4}=$ quality manager & 0.57 \\
$a_{3}$ & $C_{2}=$ schedule manager & 0.57 \\
$a_{4}$ & Veto & \\
$a_{5}$ & $C_{1}=$ cost manager & 0.54 \\
\hline
\end{tabular}

a certain amount of time with the model before executing the projects than to delay them or significantly underestimate the costs with planned projects.

Regarding the theoretical contribution, the present study covers five different categories of construction industry managers: cost manager, schedule manager, contract manager, quality manager, and project manager. The most important competencies for each class of manager are also highlighted, whereas previous studies such as Cheng et al. [16], Dainty et al. [14], and Hanna et al. [3] focused only on the PM role in order to distinguish exceptional PMs from average ones.

Cheng et al. [16] made this distinction by focusing on the role of the job (job-task competencies associated with 
the project management function) and the characteristics of the individual person (behavioral competencies linked to the managers' personal characteristics), while Hanna et al. [3] used an additive model in their research to make the same distinction. Dainty et al. [14] also used the same steps as set out in Cheng et al. [16] and only added the step of applying the model to a range of human resource management functions.

Also focusing on construction projects but without emphasizing the organizational level, Omar and Fayek [19] introduced a data aggregation method to measure qualitative competencies and performance indicators. The authors emphasize the importance of future research tackling how to develop a more advanced application of the aggregation method so that it can combine both qualitative and quantitative criteria.

Using additive aggregation models, Omar and Fayek [19] and Hanna et al. [3] consider that a PM's particular deficiency in a competence area could be compensated by another where this same PM has greater success. On the other hand, the advantage of using a noncompensatory model in this current study, where a better performance in one criterion may not compensate for a poor performance in another criterion, was that a manager's lack of one or more competencies may not be compensated by excellence in another competence. That is in line with the realities of project management, whereby a specific competence can rarely be replaced by another.

\section{Conclusion}

The model provides benefits for the construction industry, where there are many managers working together simultaneously for a company in the same project or acting at the same time on different projects. In that case, no manager is considered more important than any other. However, the range and level of competencies that they should have depend on the job assigned to them and that inevitably means the competencies they currently need to exercise will be different from each other.

This study also found that, in some companies, managers had deficient or faulty competencies. In this case, this study contributes by guiding top management on what core competencies a manager should have in order to be hired for a given position. Similarly, the model also sheds light on what kind of training needs to be developed for managers before they are appointed to such positions.

The article adds depth to the body of knowledge of classification models of unordered categories and applies the NeXClass model in the construction industry to classify managers into different categories according to their competencies. It also features a wider study of various types of competencies required in this industry and how to measure them. The questionnaire to evaluate managers can also be used as a tool for developing competencies that are necessary for each position held. Therefore, the article makes a significant contribution in the theoretical and practical sense.

Thus, the article makes a practical contribution to helping to develop construction managers professionally in the sense that it allocates a given position to the manager who is the most apt to occupy it. If a manager is weak in some competencies, the model, as it identifies these weaknesses, also offers the possibility of the company training the manager in whatever competencies are needed to act in a certain role. It is worth noting that the application is valid for assessing functions other than those needed in the company studied, in addition to the fact that the model can also be used to assess competencies that may vary from project to project.

However, the study could not measure competencies throughout the life of a project or several projects at the same time in order to determine if managers were successful in their jobs and to determine the main problems and difficulties that they encountered.

Therefore, further studies must be conducted to deepen how to identify the competencies that construction managers need, keeping in mind the fact that new classes of managers may be required for different projects. Additionally, further research also needs to monitor managers' behavior in these competencies over the course of several projects, especially for long-term projects, where more uncertainty will arise during its execution (with deadlines equal to or greater than two years).

Finally, the NeXClass model adequately classified managers in different positions according to their competencies and it can also be applied in other construction companies that have different PM positions and for which different competencies are needed.

\section{Appendix}

The questionnaire for assessing managers' competencies is given as follows (source: adapted from Ofori (2014) and Roquette and Murici (2007)).

Conceptual Thinking $\left(g_{1}\right)$

The manager:

(1) Updates and revises the project plan as needed.

(2) Plans, performs, and rapidly reaches major milestones or gates.

(3) Performs end-of-phase closure, reviews results, and updates the project documents.

(4) At project closure, evaluates and records project plan vs. actual metrics.

(5) Performs project closure, and this includes evaluating if objectives were met and lessons learned.

(6) Performs contract close-out and evaluation.

Evaluation: $\mathrm{VC}=$ the manager often performs all items; $\mathrm{C}=$ the manager performs 5 of the 6 items; $\mathrm{SC}=$ the manager performs 4 of the 6 items; $U=$ the manager performs 2 or 3 of the items; $\mathrm{NC}=$ the manager performs, at most, 1 of the 6 items. $\mathrm{VC}=$ very competent; $\mathrm{C}=$ competent; $\mathrm{SC}=$ somewhat competent; $\mathrm{U}=$ uncertain; and $\mathrm{NC}=$ not competent. 


\section{Analytical Thinking $\left(g_{2}\right)$}

The manager:

(1) Develops effective, clear, and measurable objectives.

(2) Identifies project stakeholders and maintains communication with them throughout the project.

(3) Assures a meaningful project charter that includes a vision of the needs of the business, the preliminary scope or a description of the product.

(4) Prioritizes the portfolio of projects based on the business case for each one, linkages to the company's strategy, and other factors.

(5) Ensures that the project has an unambiguous statement of scope, statement of work, or clear requirements, as appropriate.

Evaluation: $\mathrm{VC}=$ the manager often performs all items; $\mathrm{C}$ $=$ the manager performs at least 4 of the 5 items; $\mathrm{SC}=$ the manager performs 3 of the 5 items; $U=$ the manager performs 2 of the 5 items; $\mathrm{NC}=$ the manager performs, at most, 1 of the 5 items.

Initiative $\left(g_{3}\right)$

The manager:

(1) Has a positive attitude in different situations e.g. knows how and when to surprise, thrill staff which they will transmit to other employees.

(2) Anticipates facts, by carrying out activities before being asked or forced to by circumstances.

(3) Knows when to withdraw from a business in decline at the right time, thereby preserving gains or reducing losses.

(4) Is connected with the world and always receptive to information; uses certain situations to meet new demands or niches quickly, thus exploiting opportunities.

(5) As a pioneer, gets concrete and significant results before others.

Evaluation: $\mathrm{VC}=$ the manager often performs all items; $\mathrm{C}$ $=$ the manager performs at least 4 of the 5 items; $\mathrm{SC}=$ the manager performs 3 of the 5 items; $\mathrm{U}=$ the manager performs 2 of the 5 items; $\mathrm{NC}=$ the manager performs, at most, 1 of the 5 items.

Impact, Influence and Negotiation $\left(g_{4}\right)$

The manager:

(1) Is able to engage in a discussion and achieve the company's interests by influencing the decisions of others.
(2) Has the power to persuade, convince, influence or impress others, in order to support his agenda.

(3) Has effective communication skills, and knows when the right time to talk is and when to listen.

(4) Is able to focus on ideas, and does not let negotiations be influenced by personal aspects; meets the real needs and expectations.

(5) Knows how to discuss proposals, by focusing on relevant aspects, without being held up by sporadic situations.

(6) Provides alternatives to the other party.

(7) Is objective when addressing the problems to find the most appropriate solution.

(8) Makes concrete proposals to avoid doubts and misunderstandings.

Evaluation: $\mathrm{VC}=$ the manager often performs all items; $\mathrm{C}$ $=$ the manager performs at least 7 of the 8 items; $\mathrm{SC}=$ the manager performs 5 or 6 of the 8 items; $U=$ the manager performs 3 or 4 of the 8 items; $\mathrm{NC}=$ the manager performs two or fewer items.

Directivity/Assertiveness $\left(g_{5}\right)$

The manager:

(1) Has presence/authority, likes to be in control, is the leading spirit.

(2) Ensures that subordinates meet his wants.

(3) Communicates clearly and objectively, speaking and acting honestly without fear or inhibition.

(4) Stands decisively and convincingly without harming relationships, focusing on factual actions and not on agents.

(5) responds to situations positively or negatively as a result of a thorough, unbiased and wellfounded analysis of the facts.

Evaluation: $\mathrm{VC}=$ the manager often performs all items; $\mathrm{C}$ $=$ the manager performs at least 4 of the 5 items; $\mathrm{SC}=$ the manager performs 3 of the 5 items; $\mathrm{U}=$ the manager performs 2 of the 5 items; $\mathrm{NC}=$ the manager performs, at most, 1 of the 5 items.

\section{Teamwork, Cooperation and Communication $\left(g_{6}\right)$}

The manager:

(1) Demonstrates effective listening.

(2) Clearly communicates, using effective writing skills and assuring that communications look professional.

(3) Manages meetings effectively, including eliminating unneeded ones.

(4) Effectively facilitates multidisciplinary groups.

(5) Empowers the project team by removing barriers of communication. 
(6) Shares management responsibilities with the team.

(7) Holds informative, constructive, efficiently managed status review meetings.

(8) Analyzes status information to perform progress and status reporting.

(9) Keeps executive management apprised of project status (avoids surprises).

(10) Maintains a stakeholder information retrieval and distribution process.

(11) Manages effective communication for both single-site collocation and distributed teams.

Evaluation: $\mathrm{VC}=$ the manager often performs at least 10 of the 11 items; $\mathrm{C}=$ the manager executes 7 to 9 of the 11 items; $\mathrm{SC}=$ performs the manager 4 to 6 of the 11 items; $\mathrm{U}=$ the manager performs 3 of 11 items; $\mathrm{NC}=$ the manager performs two or fewer items.

\section{Team Leadership $\left(g_{7}\right)$}

The manager:

(1) Organizes the project team appropriately for the project's size.

(2) Initiates a project with a skilled project manager, the right team members, and access to the right subject area experts.

(3) Allocates staff according to portfolio priorities, applying resources with the needed skills and experience.

(4) Builds teams that perceive themselves as teams that strive to perform to their maximum potential.

(5) Builds strong teams that demonstrate the appropriate mix of team and task orientation.

(6) Assesses skill-level impacts on delegated work and arranges for mentoring or coaching.

(7) Provides adequate information while delegating assignments to team members.

(8) Delegates or refers decisions up when appropriate.

(9) Manages expectations of stakeholders, sponsor, and executive management.

(10) Demonstrates the flexibility to work with others who have different personal styles.

(11) Provides a project environment of motivation and appropriate rewards.

Evaluation: $\mathrm{VC}=$ the manager often performs at least 10 of the 11 items; $\mathrm{C}=$ the manager performs 7 to 9 of the 11 items; SC $=$ the manager performs 6 to 2 of the 11 items; $U=$ the manager performs 3 to 5 items of 11 ; NC = the manager performs two or fewer items.
Information Search $\left(g_{8}\right)$

The manager:

(1) Keeps himself informed and updated on the group processes, always seeking all relevant and useful information.

(2) Searches information for consistent decisionmaking, and knows how to process it in the form of knowledge.

(3) Performs market research, and pays attention to the news and consumer attraction factors.

(4) Evaluates competitors, knows their business strategies and their service policies.

Evaluation: $\mathrm{VC}=$ the manager often performs 4 items; $\mathrm{C}=$ the manager performs 3 of the 4 items; $\mathrm{SC}=$ the manager performs 2 of the 4 items; $U=$ the manager performs one of the four items; $\mathrm{NC}=$ the manager does not perform any of the items.

Self Control $\left(g_{9}\right)$

The manager:

(1) Copes well with pressure and stress, remains calm and in control.

Evaluation: $\mathrm{VC}=$ the manager is very competent in the execution of item 1; $\mathrm{C}=$ the manager is competent; $\mathrm{SC}=$ the manager is somewhat competent; $\mathrm{U}=$ there is uncertainty of the manager's competence; $\mathrm{NC}=$ the manager is not competent.

Flexibility and Adaptation $\left(g_{10}\right)$

The manager:

(1) Adapts quickly to change, and responds flexibly to people/situations.

Evaluation: $\mathrm{VC}=$ the manager is very competent in the execution of item 1; $\mathrm{C}=$ the manager is competent; $\mathrm{SC}=$ the manager is somewhat competent; $\mathrm{U}=$ there is uncertainty of the manager's competence; $\mathrm{NC}=$ the manager is not competent.

\section{Technical Knowledge $\left(g_{11}\right)$}

The manager:

(1) Has a clear conception of the interaction between the technical subsystem and other project elements to ensure that the project system is effectively integrated.

(2) Resolves technical problems quickly during implementation without this leading to overrunning the schedule and/or budget.

(3) Benefits from keeping him/herself continuously up-to-date in the knowledge and information necessary to carry out the work. 
(4) Solves questions with technical rigor and performs work at the standard of excellence (high quality, effective and efficient).

(5) Is highly knowledgeable about, manages and monitors the process as a whole at the institution and the unit, and focuses on desired results.

(6) Manages the organization, optimization and qualification of work processes.

Evaluation: $\mathrm{VC}=$ the manager often performs all items; $\mathrm{C}=$ the manager performs 5 of the 6 items; $\mathrm{SC}=$ the manager performs 4 of the 6 items; $\mathrm{U}=$ the manager performs 2 or 3 items; $\mathrm{NC}=$ the manager performs, at most, 1 of 6 items.

\section{Success Orientation $\left(g_{12}\right)$}

The manager:

(1) Is willing to make commitments and keeps them.

(2) Follows up to ensure decision was implemented.

(3) Tracks performance measurement criteria while working with contractors and outsourced services.

(4) Performs defect tracking, and compares progress against defect discovery rate metrics.

(5) Establishes and consistently applies a control process of useful, responsive change

(6) Plans, participates, and follows up on inspections and quality reviews.

(7) Documents and distributes plans for the phase and the project.

Evaluation: $\mathrm{VC}=$ the manager performs at least 6 of the 7 items; $\mathrm{C}=$ the manager performs 5 of the 7 items; $\mathrm{SC}=$ the manager performs 4 of the 7 items; $\mathrm{U}=$ the manager performs 2 or 3 items; $\mathrm{NC}=$ the manager performs, at most, 1 of the 7 items.

Focus on Customer Needs $\left(g_{13}\right)$

The Manager:

(1) Applies customer concepts, while focusing on quality and service.

Evaluation: $\mathrm{VC}=$ the manager is very competent in the execution of item 1; $\mathrm{C}=$ the manager is competent; $\mathrm{SC}=$ the manager is somewhat competent; $\mathrm{U}=$ there is uncertainty of the manager's competence; $\mathrm{NC}=$ the manager is not competent.

Risk Taking $\left(g_{14}\right)$

The Manager:

(1) Quantifies the likelihood and impact of risks.

(2) Facilitates the team and stakeholders in identifying risks and opportunities.
(3) Applies a consistent, repeatable project planning method that is appropriate for the size and type of project.

(4) Evaluates risk responses to assure they are appropriate and effective.

(5) Engages stakeholders in identifying phase risks and planning risk responses.

(6) Identifies and reports issues and tracks resolution of open issues.

Evaluation: $\mathrm{VC}=$ the manager often performs all items; $\mathrm{C}=$ the manager performs 5 of the 6 items; SC $=$ the manager performs 4 of the 6 items; $U=$ the manager performs 2 or the 3 items; $\mathrm{NC}=$ the manager performs at most 1 of the 6 items.

\section{Creativity and Innovation $\left(g_{15}\right)$}

The manager:

(1) Starts changes, produces ideas and creative solutions.

(2) Manages the creation of audacious solutions and brings about innovations in the institutional context.

(3) Disseminates necessary knowledge and information for innovation in work situations.

(4) Promotes an innovation culture, breaks paradigms and contributes to the team by introducing new processes, solutions, projects and work dynamics.

Evaluation: $\mathrm{VC}=$ the manager often performs 4 items; $\mathrm{C}=$ the manager performs 3 of the 4 items; $\mathrm{SC}=$ the manager performs 2 of the 4 items; $\mathrm{U}=$ the manager performs one of the four items; $\mathrm{NC}=$ the manager does not perform any of the items.

\section{Decision Making $\left(g_{16}\right)$}

The manager:

(1) Makes decisions fast, displays confidence, and acts alone when necessary.

(2) Points out alternative solutions to the problem or situation, by analyzing its implications (risks and opportunities in relation to the goal or expected result).

(3) Has the discretion to choose the most suitable alternative for the context and/or situation.

(4) Implements the chosen alternative, monitors and evaluates if result(s) of decisions were reached.

Evaluation: $\mathrm{VC}=$ the manager often performs 4 items; $\mathrm{C}=$ the manager performs 3 of the 4 items; SC = the manager performs 2 of the 4 items; $U=$ the manager performs one of the four items; $\mathrm{NC}=$ the manager does not perform any of the items. 


\section{Conflicts of Interest}

The authors declare that there are no conflicts of interest regarding the publication of this paper.

\section{Acknowledgments}

This study is part of a research program funded by the Brazilian Research Council (CNPq).

\section{References}

[1] A. Firouzi, W. Yang, and C.-Q. Li, "Prediction of total cost of construction project with dependent cost items," Journal of Construction Engineering and Management, vol. 142, no. 12, Article ID 04016072, 2016.

[2] M.-Y. Cheng, C.-W. Su, and H.-Y. You, "Optimal project organizational structure for construction management," Journal of Construction Engineering and Management, vol. 129, no. 1, pp. 70-79, 2003.

[3] A. S. Hanna, M. W. Ibrahim, W. Lotfallah, K. A. Iskandar, and J. S. Russell, "Modeling project manager competency: an integrated mathematical approach," Journal of Construction Engineering and Management, vol. 142, no. 8, Article ID 4016029, 2016.

[4] J. S. Russell, E. J. Jaselskis, and S. P. Lawrence, "Continuous assessment of project performance," Journal of Construction Engineering and Management, vol. 123, no. 1, pp. 64-71, 1997.

[5] D. Ofori, "An exploratory study of project management competency in Ghana," Journal of African Business, vol. 15, no. 3, pp. 197-210, 2014.

[6] M. Jantti and N. Greenhalgh, "Leadership competencies: a reference point for development and evaluation," Library Management, vol. 33, no. 6, pp. 421-428, 2012.

[7] M. Young and V. Dulewicz, "A study into leadership and management competencies predicting superior performance in the British Royal Navy," Journal of Management Development, vol. 28, no. 9, pp. 794-820, 2009.

[8] R. Müller and J. R. Turner, "Attitudes and leadership competences for project success," Baltic Journal of Management, vol. 5, no. 3, pp. 307-329, 2010.

[9] F. Zhang, J. Zuo, and G. Zillante, "Identification and evaluation of the key social competencies for Chinese construction project managers," International Journal of Project Management, vol. 31, no. 5, pp. 748-759, 2013.

[10] P. Ramos, C. Mota, and L. Corrêa, "Exploring the management style of Brazilians project managers," International Journal of Project Management, vol. 34, no. 6, pp. 902-913, 2016.

[11] A. Rashidi, F. Jazebi, and I. Brilakis, "Neurofuzzy genetic system for selection of construction project managers," Journal of Construction Engineering and Management, vol. 137, no. 1, pp. 17-29, 2011.

[12] R. S. C. Goodwin, "Skills required of effective project managers," Journal of Management in Engineering, vol. 9, no. 3, pp. 217-226, 1993.

[13] S. K. Gushgari, P. A. Francis, and J. H. Saklou, "Skills critical to long-term profitability of engineering firms," Journal of Management in Engineering, vol. 13, no. 2, Article ID 12358, pp. 46-56, 1997.

[14] A. R. J. Dainty, M.-I. Cheng, and D. R. Moore, "Competencybased model for predicting construction project managers' performance," Journal of Management in Engineering, vol. 21, no. 1, pp. 2-9, 2005.

[15] F. T. Edum-Fotwe and R. McCaffer, "Developing project management competency: perspectives from the construction industry," International Journal of Project Management, vol. 18, no. 2, pp. 111-124, 2000.

[16] M.-I. Cheng, A. R. J. Dainty, and D. R. Moore, "What makes a good project manager?" Human Resource Management Journal, vol. 15, no. 1, pp. 25-37, 2005.

[17] G. Ryan, L. M. Spencer, and U. Bernhard, "Development and validation of a customized competency-based questionnaire: linking social, emotional, and cognitive competencies to business unit profitability," Cross Cultural Management, vol. 19, no. 1, pp. 90-103, 2012.

[18] D. Arditi and G. Balci, "Managerial competencies of female and male construction managers," Journal of Construction Engineering and Management, vol. 135, no. 11, pp. 1275-1278, 2009.

[19] M. N. Omar and A. R. Fayek, "A framework for identifying and measuring competencies and performance indicators for construction projects," in Proceedings of the Construction Research Congress: Construction in a Global Network, CRC '14, pp. 20432052, USA, May 2014.

[20] A. T. de Almeida, C. A. V. Cavalcante, M. H. Alencar, R. J. P. Ferreira, A. T. de Almeida-Filho, and T. V. Garcez, Multicriteria and Multiobjective Models for Risk, Reliability and Maintenance Decision Analysis, vol. 231 of International Series in Operations Research \& Management Science, Springer, New York, NY, USA, 2015.

[21] G. Rigopoulos, D. T. Askounis, and K. Metaxiotis, "NeXCLass: a decision support for non-ordered multicriteria classification," International Journal of Information Technology \& Decision Making, vol. 9, no. 1, pp. 53-79, 2010.

[22] R. S. Mansfield, Practical questions in building competency models, http://www.workitect.com/pdf/PracticalQuestions.pdf, 2005.

[23] P. Sandwith, "A hierarchy of management training requirements: the competency domain model," Public Personnel Management, vol. 22, no. 1, pp. 43-62, 1993.

[24] M. Millar, Z. Mao, and P. Moreo, "Hospitality management educators vs. the industry: a competency assessment," in Proceedings of the Hospitality Management, vol. 22, University of San Francisco, San Francisco, Calif, USA, 2008.

[25] C. Margerison, “Team competencies," Team Performance Management: An International Journal, vol. 7, no. 7-8, pp. 117-122, 2001.

[26] V. Dulewicz and M. J. Higgs, Design of a New Instrument to Assess Leadership Dimensions and Styles, Henley Working Paper 0311, Henley Management College, Henley, UK, 2003, available at: https://www.henley.ac.uk/.

[27] M. Doumpos and C. Zopounidis, "Multicriteria classification methods in financial and banking decisions," International Transactions in Operational Research, vol. 9, no. 5, pp. 567-581, 2001.

[28] B. Roy, "The outranking approach and the foundations of ELECTRE methods," Theory and Decision. An International Journal for Multidisciplinary Advances in Decision Science, vol. 31, no. 1, pp. 49-73, 1991.

[29] J. R. Figueira, S. Greco, B. Roy, and R. Slowinski, "ELECTRE Methods: Main Features and Recent Developments," in Handbook of Multicriteria Analysis, vol. 103 of Applied Optimization, pp. 51-89, Springer Berlin Heidelberg, Berlin, Heidelberg, 2010. 
[30] R. P. Palha, A. T. De Almeida, and L. H. Alencar, "A model for sorting activities to be outsourced in civil construction based on ROR-UTADIS," Mathematical Problems in Engineering, vol. 2016, Article ID 9236414, 15 pages, 2016.

[31] N. Belacel, "Multicriteria assignment method PRO AFTN: methodology and medical application," European Journal of Operational Research, vol. 125, no. 1, pp. 175-183, 2000.

[32] F. Al-Obeidat, N. Belacel, J. A. Carretero, and P. Mahanti, "Differential Evolution for learning the classification method PROAFTN," Knowledge-Based Systems, vol. 23, no. 5, pp. 418426, 2010.

[33] The Committee on Construction Management, "Qualification and selection of construction managers with suggested guidelines for selection process," Journal of Construction Engineering and Management, vol. 113, no. 1, pp. 51-89, 1987.

[34] P. D. Rwelamila, "Group dynamics and construction project manager," Journal of Construction Engineering and Management, vol. 120, no. 1, pp. 3-10, 1994.

[35] J. Figueira and B. Roy, "Determining the weights of criteria in the ELECTRE type methods with a revised Simos' procedure," European Journal of Operational Research, vol.139, no. 2, pp. 317326, 2002. 


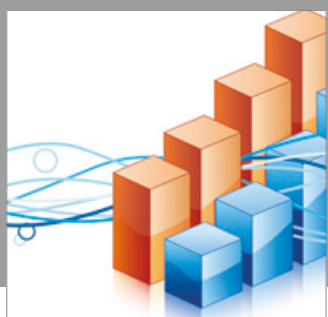

Advances in

Operations Research

vatersals

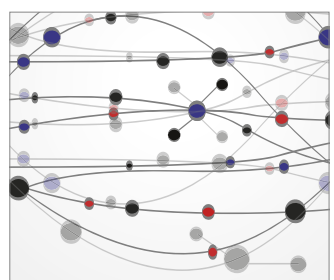

\section{The Scientific} World Journal
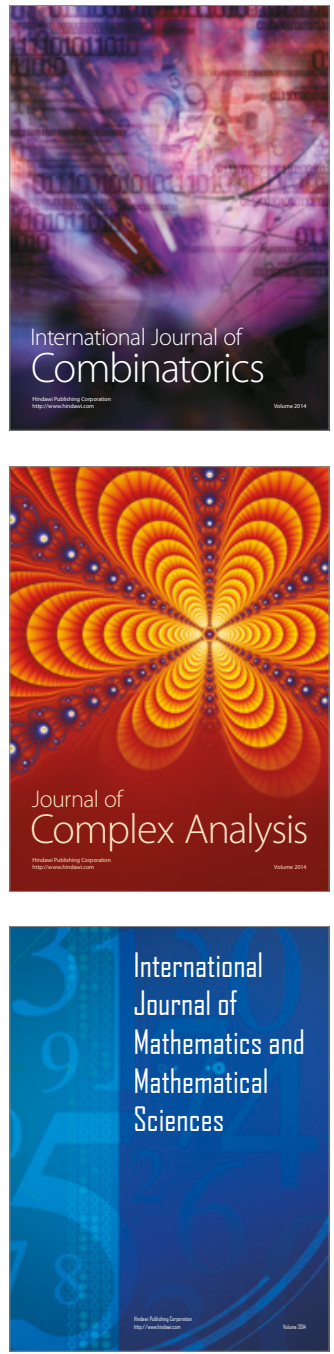
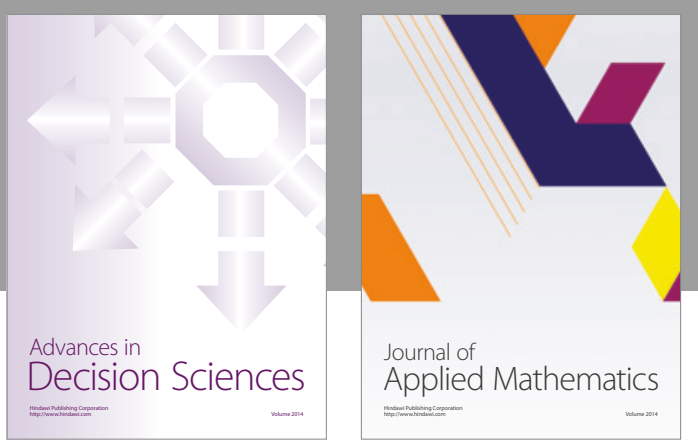

Algebra

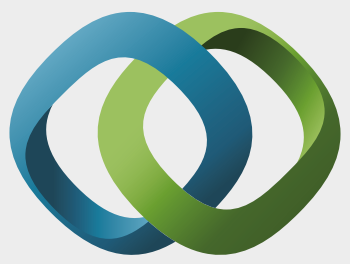

\section{Hindawi}

Submit your manuscripts at

https://www.hindawi.com
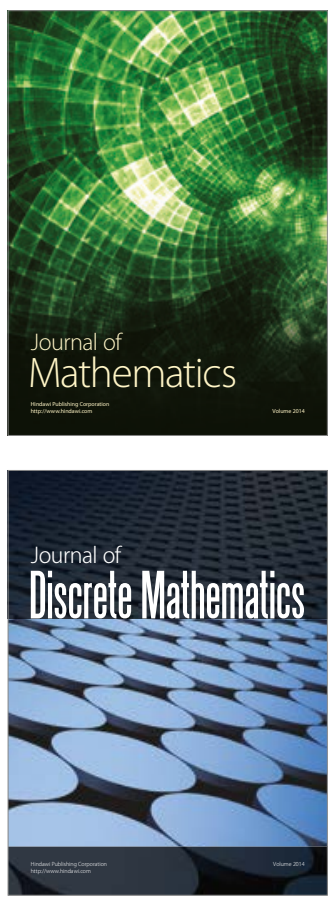

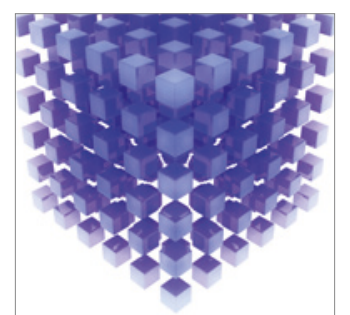

Mathematical Problems in Engineering
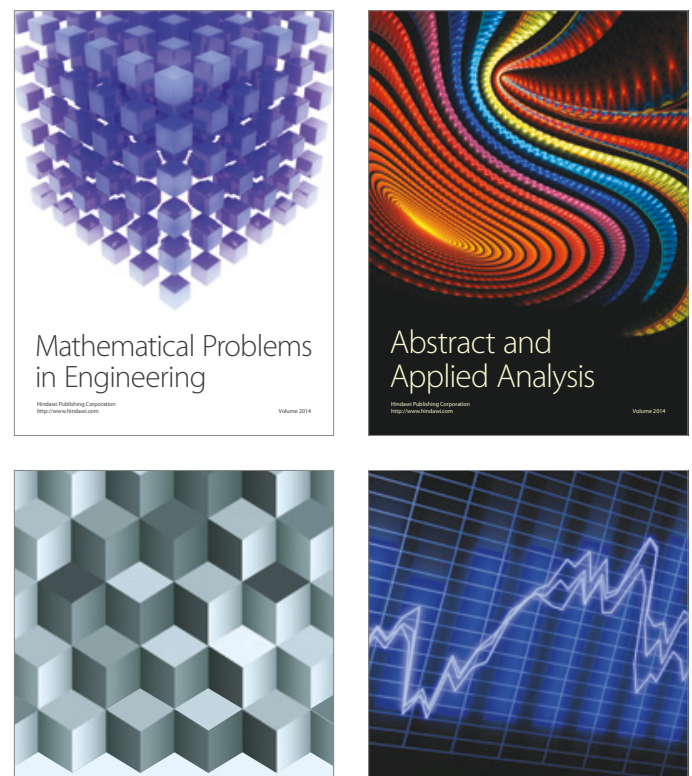

Journal of

Function Spaces

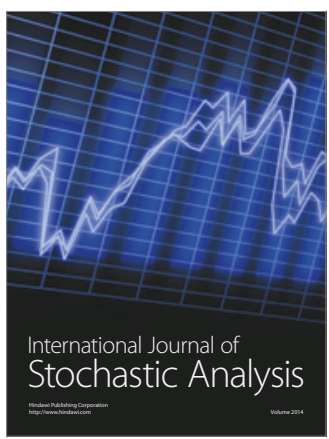

Probability and Statistics
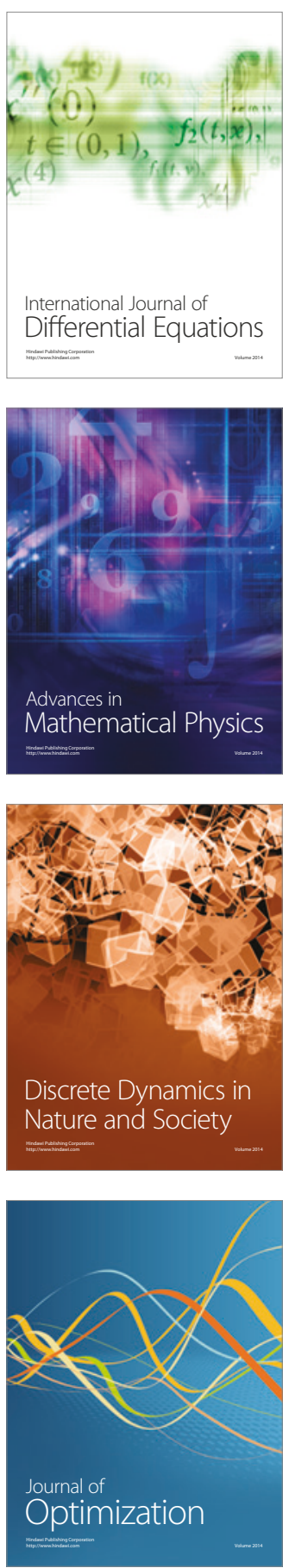